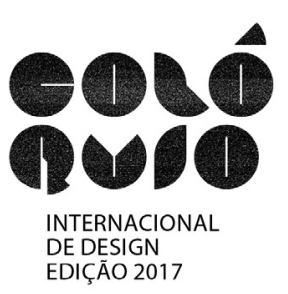

\title{
A Contribuição da Gestão de Design para a Sustentabilidade Empresarial.
}

\author{
Larissa Fontoura Berlato; \\ Giselle Schmidt Alves Díaz Merino; \\ Luiz Fernando Gonçalves Figueiredo.
}

resumo:

A sociedade contemporânea necessita de uma mudança de paradigmas a ser posta em prática pela sociedade. Faz-se necessário rever nosso modo de vida e reinventar os modelos de produção, de desenvolvimento e de consumo, conciliando as dimensões econômica, ambiental e social nos negócios, para que as empresas prosperem e nosso futuro tenha garantia. Segundo Manzini (2006), precisamos encontrar um novo estilo de vida consentâneo com o paradigma da sustentabilidade. Entende-se por desenvolvimento sustentável a procura da satisfação das necessidades presentes de produção e de consumo, sem comprometer a capacidade das gerações futuras de suprirem suas próprias necessidades. O Design é uma atividade criativa cujo objetivo é estabelecer as qualidades multifacetadas de objetos, processos, serviços e seus sistemas em todo o ciclo de vida (ICSID). $\mathrm{Na}$ era da produção em massa, onde tudo deve ser planejado e projetado, o Design se tornou um dos mais poderosos instrumentos com que o homem dá forma a suas ferramentas e ao seu ambiente, por extensão, à sociedade e a si próprio (PAPANEK, 1995). O Design consiste na melhoria da qualidade de uso do produto, da forma de um novo produto, do seu processo de fabricação, da sustentabilidade ambiental e social, da forma de acesso a um produto socialmente inclusivo, da aplicação de novos materiais e da qualidade estética (BONSIEPE, 1997). Manzini e Vezzoli (2008) defendem que o produto deve ser projetado considerando, em todas as suas fases, o conceito de ciclo de vida, ou seja, todas as atividades necessárias para produzir, distribuir, utilizar e eliminar/descartar um produto são consideradas uma unidade só. A Gestão de Design surgiu, ainda que voltada para a competitividade, da percepção de que a atividade de Design pode contribuir para com a orientação empresarial através de seu caráter projetual, no que diz respeito ao arranjo de fatores que determinem um trajeto inovador rumo a um objetivo (MARTINS e MERINO, 2011). Este trabalho, de cunho teórico, objetiva analisar a contribuição da Gestão de Design como promotor de melhorias sociais, ambientais e econômicas no contexto empresarial, enquanto avalia a influência da adoção de práticas responsáveis para a sustentabilidade empresarial e seu sucesso no âmbito mercadológico, filosófico e financeiro. Para tanto, o presente artigo apresenta uma revisão bibliométrica e uma análise acerca dos pressupostos teóricos que balizam as temáticas que envolvem desenvolvimento sustentável, sustentabilidade empresarial, Gestão de Design e Gestão sustentável de Design. Esta pesquisa divide-se em duas etapas: em um primeiro momento faz a revisão sobre os temas, para logo a seguir analisar a relação entre os temas abordados, identificando os recursos e as competências da Gestão de Design, visando a melhoria da performance sustentável nas empresas.

palavras-chave:

Desenvolvimento sustentável; Empresas; Gestão de Design. 


\section{Introdução}

Os modelos de produção e consumo utilizados desde a Revolução Industrial, bem como os valores que os sustentam, estão em desacordo com as bases necessárias para a manutenção de um ambiente sadio, pois vêm comprometendo o futuro do nosso planeta. A crescente extração dos recursos naturais, a vulnerabilidade da fauna e da flora, o aquecimento global, o efeito estufa e o crescimento demográfico mundial têm gerado impactos avassaladores na sociedade e no meio ambiente. Junta-se a isso, uma crise econômica mundial que vem aumentando os níveis de pobreza e de desemprego em diversos países, inclusive nos considerados de Primeiro Mundo.

De acordo com Brundtland (1987), a presente década tem sido marcada por preocupações sociais. Os cientistas chamam atenção para problemas urgentes e complexos que comprometem a nossa própria sobrevivência. A degradação ambiental, visto pela primeira vez como um problema principalmente das nações ricas e um efeito colateral da riqueza industrial, tornou-se uma questão de sobrevivência para as nações em desenvolvimento. E como parte do nosso "desenvolvimento", temos acumulado arsenais capazes de desviar o caminho que a evolução tem seguido por milhões de anos e de criar um planeta que nossos antepassados não reconheceriam.

Tendo em mente que os recursos naturais são finitos e que, no modelo econômico atual, as empresas exercem grande influência sobre os recursos humanos, sociais e ambientais, o desenvolvimento sustentável como prática na sociedade e no mundo corporativo é essencial para a melhoria da qualidade de vida de todos. Segundo Manzini (2006), um dos principais objetivos deve ser o de encontrar um novo estilo de vida consentâneo com o paradigma da sustentabilidade.

"O que é necessário agora é uma nova era de crescimento econômico, crescimento que seja forte e ao mesmo tempo socialmente e ambientalmente sustentável (Brundtland, 1987, p. 7).”

Esse cenário econômico, social e ambiental está gerando transformações na sociedade, e o tema sustentabilidade vem crescendo em importância não somente para os cidadãos como também para as empresas. De acordo com Kotler, Kartajaya e Setiawan (2010, p. 22), "a era do Marketing 3.0 é aquela em que as práticas de marketing são muito influenciadas pelas mudanças no comportamento e nas atitudes do consumidor, que demanda abordagens de marketing mais colaborativas, culturais e espirituais." Nessa nova era do marketing, os autores afirmam que, as empresas devem se mostrar socialmente responsáveis, além da razão e da emoção, preocupar-se com o mundo, com o planeta e com as boas práticas.

Segundo Barbiere et al (2010), diferente do ocorrido com o movimento de qualidade, a adesão das empresas ao desenvolvimento sustentável vem inicialmente de fora para dentro, como um meio de se contrapor às críticas e objeções ao papel das empresas feitas por entidades governamentais e pela sociedade civil organizada, responsabilizando-as pelos processos de degradação social e ambiental que atingem todo o planeta. Só recentemente a adesão das empresas passou a ser induzida por fatores de natureza empresarial visto que, fazer parte desse movimento passou a ser um fator de competitividade, seja como fonte de diferenciação, seja como fonte de qualificação para continuar no mercado.

Uma pesquisa realizada pela Economist Intelligence Unit, com 1.254 executivos de todo o mundo, corroborou com a relação entre sustentabilidade e performance financeira das empresas. Os empresários que afirmaram ter reduzido impactos sociais e ambientais relataram um aumento anual de $16 \%$ nos lucros e aumento de $45 \%$ no valor das ações, enquanto as empresas que não investiram na sustentabilidade tiveram crescimento anual de $7 \%$ nos lucros e aumento de $12 \%$ no valor das ações (The Economist, 2008).

Este trabalho tem como principal objetivo analisar a contribuição da Gestão de Design como promotor de melhorias sociais, ambientais e econômicas no contexto empresarial, enquanto avalia a influência da adoção das práticas de sustentabilidade empresarial para o sucesso no âmbito mercadológico, filosófico e financeiro nas empresas.

\section{Procedimentos Metodológicos}

Essa pesquisa é exploratória e como procedimento metodológico foi realizado uma revisão literária e uma análise acerca dos pressupostos teóricos que balizam as temáticas que envolvem desenvolvimento sustentável, sustentabilidade empresarial, Gestão de Design e Gestão sustentável de Design. O 
delineamento desse estudo foi feito por meio de uma pesquisa bibliográfica em periódicos, artigos científicos e livros.

Esta pesquisa divide-se em duas etapas: em um primeiro momento faz a revisão sobre os temas, para logo a seguir analisar a relação entre os temas abordados, identificando os recursos e as competências da Gestão de Design, visando a melhoria da performance sustentável nas empresas.

\section{Fundamentação Teórica}

\subsection{A necessidade de mudança para um desenvolvimento sustentável}

A Era Industrial marca o início do desenvolvimento do capitalismo industrial, do crescimento da produção em massa e do surgimento de novas populações urbanas. Esse modelo econômico não estava atento aos impactos adversos do que se produzia e consumia. Por um lado, as empresas tendo como único objetivo a minimização dos custos e a maximização dos lucros e, por outro, o surgimento de uma ideologia consumista na sociedade.

De acordo com Manzini (2006), a noção de bem-estar nas últimas décadas foi associada ao poder de consumo que se fez sentir nas sociedades desenvolvidas, promovido pelos avanços tecnológicos e científicos, proporcionando uma panóplia de novos tipos de produtos que ao longo do tempo foram sendo integrados na sociedade transmitindo uma melhoria constante da qualidade de vida. $\mathrm{O}$ alto consumo de produtos e serviços, que não tinham sido projetados com a consciência que nos dias de hoje se procura incessantemente implementar, responsabiliza em grande parte os seus autores e quem os comissiona pelos impactos ambientais e sociais globais. Complementando, acrescenta-se o que diz Castells (1999, p.141), "a maioria de nossos problemas ambientais mais elementares ainda persistem, uma vez que seu tratamento requer uma transformação nos meios de produção industriais e de consumo, bem como de nossa organização social e de nossas vidas pessoais."

"Na sociedade atual, os valores ligados ao desenvolvimento sustentável e ao respeito às políticas ambientais têm sido institucionalizados em maior ou menor grau nos diversos países pela mídia, pelos movimentos sociais e ambientalistas, e pelos governos (BARBIERI et al, 2010, p.149).

Segundo Pinheiros (2006), a responsabilidade pelo desenvolvimento sustentável do planeta está repartida entre governos, organizações e sociedade. O autor ressalta que as ações das organizações na preservação ambiental são deveras importante, uma vez que as indústrias possuem recursos financeiros e tecnológicos, além de competência institucional e visão de longo prazo para solucionar seus problemas ambientais. Os governos, por seu turno, têm avançado em melhorias na gestão social e ambiental por meio de novas políticas sociais e de preservação do meio ambiente, bem como com a criação de regulamentação e fiscalização nessas áreas.

A respeito do comportamentos de quem consome, afirmam Kotler, Kartajaya e Setiawan (2010), que cada vez mais, os consumidores estão buscando soluções para satisfazer seu anseio de transformar o mundo globalizado num mundo melhor. De acordo com um estudo feito pelo Instituto Akatu (2009), o consumidor consciente tem como principal característica a análise crítica feita no momento da escolha de consumo no que se refere aos impactos socioambientais que o seu ato de compra, de uso ou descarte de um produto ou serviço pode vir a causar. Nesse sentido, ele procura equilibrar suas necessidades pessoais com as necessidades da sociedade e as possibilidades do planeta.

Uma pesquisa realizada pela empresa Nielsen, com mais de 29.000 consumidores on-line em 58 países, afirma que $55 \%$ dos respondentes estariam dispostos a pagar mais por produtos e serviços de empresas que estão comprometidas com as questões sociais e ambientais - um crescimento na taxa de $50 \%$ em 2012 e $45 \%$ em 2011. Com o intuito de confirmar essa performance no mercado, em março de 2014 a Nielsen revisou os dados de vendas do mercado em nove países, fazendo uma comparação com os resultados do ano anterior, e as marcas que incluíram apelos sustentáveis na embalagem tiveram um crescimento de vendas de $2 \%$ ao ano, enquanto as marcas que promoviam a sustentabilidade por meio de ações de marketing tiveram um crescimento de vendas de $5 \%$ ao ano. As marcas que não têm nenhum apelo de sustentabilidade têm um crescimento de apenas $1 \%$ ao ano (NIELSEN GLOBAL REPORT, 2014).

O contexto atual possibilita uma nova dinâmica para o mundo, que revê nosso modo de vida e reinventa os modelos de produção, de desenvolvimento e de consumo, conciliando as dimensões 
econômica, ambiental e social nos negócios com a prosperidade das empresas e a preservação de nosso futuro em uma sociedade mais justa e sustentável.

\subsection{Sustentabilidade e desenvolvimento sustentável}

Em 1972, o Clube de Roma publica "Limites do crescimento", um relatório realizado pelo MIT (Massachusetts Institute of Technology) que ressaltava a importância da contenção do crescimento e a adoção da política do "crescimento zero" para todos os países. O relatório teve um enorme impacto, tornando pública a problemática ambiental e inserindo a questão ambiental na agenda política mundial.

Foi a partir do relatório divulgado pela Sra. Brundtland, ex-Primeira Ministra da Noruega, sob o nome de "Nosso futuro comum", que a expressão "Desenvolvimento sustentável" ganhou notoriedade (CMMAD, 1991). Esse documento foi a base das discussões da Conferência das Nações Unidas para o Meio Ambiente e o Desenvolvimento (CNUMAD), mais conhecida como ECO 92 ou RIO 92, uma conferência promovida pela ONU no Rio de Janeiro, em 1992. O principal objetivo deste encontro foi o incentivo à mobilização das nações mundiais para a formulação e integração de um plano de ação com o intuito de impulsionar a criação de novas políticas governativas, focando em especial a consideração da proteção ambiental como princípio de desenvolvimento e a sensibilização para os padrões insustentáveis de consumo e produção nos países industrializados (UNDSD, 1992).

O movimento pelo desenvolvimento sustentável parece ser um dos movimentos sociais mais importantes deste início de século e milênio. São incontáveis as iniciativas voluntárias relacionadas ao desenvolvimento sustentável por parte das empresas, bem como as elaborações de cartas de princípios e diretrizes de ação como a Carta de Rotterdam, as Metas do Milênio e o Pacto Global (BARBIERI et al, 2010).

Desenvolvimento sustentável, de acordo com o Relatório Bruntland, é o desenvolvimento que procura satisfazer as necessidades da geração atual, sem comprometer a capacidade das gerações futuras de satisfazer as suas próprias necessidades. Isso significa possibilitar que as pessoas, agora e no futuro, atinjam um nível satisfatório de desenvolvimento social e econômico e de realização humana e cultural, fazendo, ao mesmo tempo, um uso razoável dos recursos da terra e preservando as espécies e os habitats naturais. O relatório também propõe uma atuação conjunta dos governos, empresas e sociedade na busca de soluções sustentáveis (BRUNDTLAND, 1987).

Sustentabilidade pode ser entendida como a preservação do bem comum, baseando-se nos quatro princípios fundamentais da Carta da Terra, aprovada no espaço UNESCO, em Paris, no ano de 2000: (1) respeito e cuidado da comunidade de vida; (2) integridade ecológica; (3) justiça social e econômica; (4) democracia, não violência e paz (LOUETTE, 2008).

Segundo Sachs (2002), para que haja desenvolvimento sustentável é necessário o cumprimento da satisfação das necessidades básicas, solidariedade com as gerações futuras, participação da população envolvida, preservação dos recursos naturais e do meio ambiente, elaboração de um sistema social que garanta emprego, segurança social e respeito a outras culturas, e programas de educação.

O desenvolvimento sustentável abrange várias dimensões das atividades humanas, buscando um equilíbrio entre o crescimento econômico, a equidade social e a proteção do meio-ambiente, o chamado Tripé da Sustentabilidade.

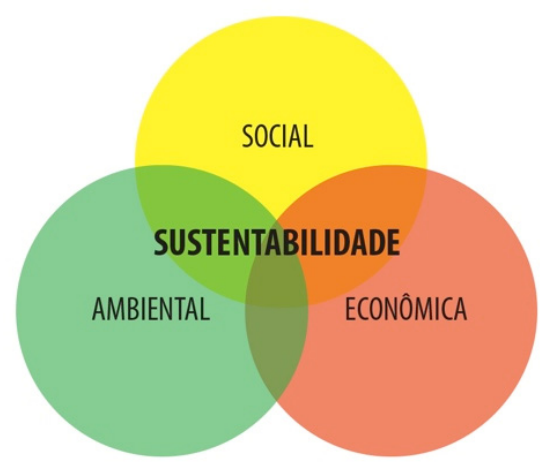

Figura I: Tripé da Sustentabilidade

Fonte: Adaptação dos três pilares de Elkington (1997). 
Dimensão Econômica: transparência contábil, governança corporativa, performance econômica e objetivos financeiros.

Dimensão Social: políticas públicas, investimentos comunitários, direitos dos trabalhadores, direitos humanos, investimento social responsável, respeito ao consumidor, transparência e postura ética.

Dimensão Ambiental: proteção ambiental, preservação dos recursos naturais e biodiversidade, uso de recursos renováveis, ecoeficiência, análise do ciclo de vida dos produtos, gestão de resíduos e gestão de riscos.

\subsection{Relatório de Sustentabilidade}

A definição de negócio sustentável, de acordo com o Instituto Ethos de Empresas e Responsabilidade Social, gira em torno de uma atividade econômica orientada para a geração de valor econômicofinanceiro, ético, social e ambiental, cujos resultados são compartilhados com os públicos afetados. Sua produção e comercialização são organizadas de modo a reduzir continuamente o consumo de bens naturais e de serviços ecossistêmicos, a conferir competitividade e continuidade à própria atividade e a promover e manter o desenvolvimento sustentável da sociedade.

Uma empresa para ser sustentável deve buscar em todas as suas ações e decisões a ecoeficiência, procurando produzir mais e com melhor qualidade, gerando menos poluição e utilizando menos recursos naturais. A empresa que é partidária dos princípios da sustentabilidade deve ainda ser socialmente responsável, assumindo que está imersa num ambiente social em que influi ao mesmo tempo em que sofre influência. A motivação dos líderes empresariais deve ser respaldada numa visão de longo prazo, em que se leve em consideração os custos futuros e não somente os custos presentes (ALMEIDA, 2002).

De acordo com Barbiere et al (2010), ao se comprometer com o desenvolvimento sustentável, a empresa deve necessariamente alterar a sua forma de atuação para, no mínimo, reduzir os impactos sociais e ambientais negativos. Dessa forma, faz-se necessário uma nova maneira de encarar a inovação, o que leva à ideia de inovação sustentável, ou seja, um tipo de inovação que contribua para o alcance do desenvolvimento sustentável. Uma organização inovadora sustentável não é a que introduz novidades de qualquer tipo, mas novidades que atendam as múltiplas dimensões da sustentabilidade em bases sistemáticas e colham resultados positivos para ela, para a sociedade e o meio-ambiente.

Uma empresa sustentável deve estar atenta as suas ações em todas as dimensões do desenvolvimento sustentável: econômica, social e ambiental. O objetivo primordial da empresa continua sendo o lucro, base fundamental da sua existência. Entretanto, o desenvolvimento sustentável como estratégia de negócio faz com que a empresa concilie as questões sociais e ambientais com os seus resultados financeiros. O sucesso da empresa não está mais ligado somente a sua capacidade de produção, mas também a sua participação mais ampla na sociedade, nas esferas sociais e ambientais.

A inclusão dos aspectos sociais e ambientais nos relatórios corporativos, o chamado Triple Bottom Line (People, Planet, Profit), no qual os resultados de uma empresa são medidos em termos sociais, ambientais e econômicos, é também um reconhecimento da importância da sustentabilidade empresarial,

"O crescimento econômico é algo sempre desejado e perseguido por empresários e políticos, o que explicaria a grande adesão que eles deram ao movimento de sustentabilidade (BARBIERI et al, 2010, p.148)."

No campo social e ambiental, são desenvolvidos programas e projetos sociais, ambientais e sustentáveis, tecnologias e produtos verdes. No campo empresarial, a empresa melhora seus relacionamentos com seus diversos públicos-alvo, programa modelos de negócios sustentáveis e presta conta de suas ações através de relatórios e balanços.

Para que as empresas tenham o reconhecimento dos seus esforços em termos de sustentabilidade é necessária uma visão de longo prazo, focada em questões significativas, que tragam benefícios reais para a sociedade e para o ambiente. Esse tipo de gestão deve considerar o resultado de suas atividades para com todos os stakeholders: funcionários, colaboradores, fornecedores, clientes, consumidores, investidores, concorrentes, governo e comunidade. As empresas comprometidas são 
coerentes e atuam com transparência e honestidade, utilizando-se de práticas reais e mensuráveis e comunicando suas ações e atitudes de forma clara e objetiva.

"No âmbito das organizações em geral, e em especial das empresas, esse processo de institucionalização não teve precedentes, seja em termos de abrangência espacial, seja em termos de rapidez com que o conceito se popularizou nesse meio (BARBIERI et al, 2010, p.149).”

Em nível institucional, ao se posicionar no mercado como uma empresa comprometida com as questões sociais e ambientais, ela faz da sua imagem o seu principal fator de competitividade, valorizando seus produtos, seus serviços e sua marca. Essa responsabilidade social corporativa cria um relacionamento mais próximo com o consumidor, reforçando a reputação da empresa ao encorajar a lealdade e transmitir valores positivos. Essa responsabilidade social perpassa por todos os níveis organizacionais, desde a estratégia a ser adotada até a operação de venda, atribuindo à empresa um caráter mais humano e altruísta por ter interesses maiores. Adotando essa nova forma de pensar e agir, a organização está buscando dar a sua contribuição para a sociedade (ALESSIO, 2008).

Há alguns anos, iniciou-se uma tendência mundial de investidores procurarem empresas socialmente responsáveis, sustentáveis e rentáveis para aplicar seu dinheiro. Em 1999, Dow Jones nos Estados Unidos foi a primeira Bolsa de Valores a incorporar sustentabilidade nos seus produtos Índice Dow Jones de Sustentabilidade. Esse índice pondera a importância da integração dos fatores econômicos, ambientais e sociais na estratégia da empresa e avalia aspectos como inovação tecnológica, governança corporativa, interesse dos investidores, expectativas dos públicos de interesse, liderança e capacidade de resposta às mudanças sociais (LOUETTE, 2008).

No Brasil, em 2005, ocorreu o lançamento do Índice de Sustentabilidade Empresarial - ISE, pela Bovespa, que considera o desempenho financeiro, social, ambiental e de governança corporativa de companhias listadas na Bolsa. O ISE tem como objetivo refletir o retorno de uma carteira composta por ações de empresas com reconhecido comprometimento com a responsabilidade empresarial e, também, atuar como promotor das práticas de sustentabilidade no meio empresarial brasileiro (LOUETTE, 2008). A nova carteira reúne 51 ações de 40 companhias que representam 18 setores e somam R\$ 1,14 trilhão em valor de mercado, o equivalente a 47,16\% do total do valor das companhias com ações negociadas na BM\&FBOVESPA com base no fechamento de 26/11/2013 (BOVESPA, 2014).

\subsection{Gestão de Design}

De acordo com a Associação Internacional de Design de Produto, International Council of Societies of Industrial Design - ICSID: O Design é uma atividade criativa cujo objetivo é estabelecer as qualidades multifacetadas de objetos, processos, serviços e seus sistemas em todo o ciclo de vida. Portanto, Design é o fator central da humanização inovadora de tecnologias e o fator crucial de intercâmbio cultural e econômico (...) O Design procura descobrir e investigar as relações estruturais, organizacionais, funcionais, expressivas e econômicas, com o intuito de aumentar a sustentabilidade global e a proteção ambiental (ética global); prover benefícios e liberdade a toda comunidade humana, individual e coletiva, usuários finais, produtores e protagonistas de mercado (ética social); apoiar a diversidade cultural apesar do processo de globalização mundial (ética cultural); e fornecer produtos, serviços e sistemas, com aquelas formas que são expressivas (semiótica) e coerentes com sua complexidade (estética).

A Associação Americana de Design de Produto, Industrial Designers Society of America IDSA, define Design como: Desenho Industrial é o serviço profissional de criar e desenvolver conceitos e especificações que aperfeiçoam a função, valor e aparência de produtos e sistemas para o benefício mútuo de ambos usuário e fabricante.

Martins e Merino (2011), afirmam que o objetivo do Design consiste em pensar e pesquisar a coerência do sistema de objetos, otimizando as soluções bem como os processos que as envolvem, concebe marcas, espaços ou objetos para satisfazer necessidades específicas segundo um processo lógico.

Nesse sentido, Bahiana (1998) afirma que, os investimentos voltados para a área de Design deixaram de ser uma questão estética para se tornarem uma questão estratégica onde as técnicas de Gestão de Design resultam em produtos diferenciados e racionalização de custos de produção. $\mathrm{O}$ potencial da Gestão estratégica deve ser incorporado ao processo de produção desde a concepção da 
estratégia da empresa, passando pela concepção do produto e em todas as fases do ciclo de vida, integrado com outras áreas, e sob todos os aspectos, em que o Design possa ser aplicado, como marca, identidade visual, embalagem do produto, embalagem de transporte, comunicação, material de apoio de vendas, arquitetura, entre outras, ao que se chama Gestão de Design.

Segundo Mozota (2011), o processo de Gestão do Design teve origem na Inglaterra nos anos 60, na época o termo significava o gerenciamento de relações entre um escritório de Design e seus clientes. A Gestão do Design está diretamente relacionada à mudança de um modelo de administração taylorista, hierárquico, para uma organização flexível, que incentiva a autonomia, a iniciativa e a tomada de decisões de risco. Esse novo modelo de gestão é orientado ao usuário, baseado em projetos e qualidade total, onde as habilidades "específicas" do designer (criatividade, iniciativa, atenção ao detalhe, atenção ao cliente) tornam-se qualidades que um gerente pode utilizar na mudança da empresa.

De acordo com Wolf (1998, p.18), a Gestão de Design possui a função de "planejar e coordenar as estratégias correspondentes aos objetivos e valores da empresa, motivar os empregados e controlar os trabalhos, assegurando que cumpram com os objetivos, com os prazos e os custos planejados".

Mozota (2011), afirma que a Gestão do Design deve ser uma ferramenta que integre as funções operacionais do Design desenvolvido em todos os setores da empresa, visando atingir os objetivos traçados e propiciar a percepção de uma imagem positiva. Coordena seus produtos e suas comunicações, ambientes e serviços. Como comunica os valores e a filosofia da empresa para o ambiente em que atua, deve estabelecer uma política que se manifeste por meio de um Design corporativo consistente, atingindo, assim, uma unidade em seu discurso, facilidade na identificação de sua mensagem e possibilitando índices de memorização que favoreçam o comportamento de troca. A dinâmica das empresas requer um monitoramento continuado do processo para que os produtos possam ser redesenhados, reposicionados, reduzidos, retirados do mercado ou deixados como estão. Genericamente, as empresas que apresentam as características que mais favorecem o Design são aquelas que se adiantam em relação a mudanças ou a pressões do seu ambiente de atuação, e possuam uma cultura propícia à inovação.

Segundo Martins e Merino (2011, p.148), "a característica distintiva da Gestão de Design é a identificação e a comunicação de caminhos pelos quais o Design pode contribuir ao valor estratégico da empresa."

No cenário atual, de competição empresarial acirrada, a Gestão de Design com sua característica estratégica, integradora e multidisciplinar, se apresenta como uma ferramenta importante para melhorias não somente no desenvolvimento de novos produtos mas também nos aspectos ligados a análise e diagnóstico das empresas, ao gerenciamento, a melhoria das práticas e processos organizacionais, ao aumento da qualidade, a redução de custos e a percepção de valor no mercado. A Gestão de Design é um conjunto de atividades de diagnóstico, coordenação e design que devem interagir em todos os setores da empresa.

O Design pode estar presente nos níveis estratégico, tático e operacional, estabelecendo objetivos de longo-prazo e em tomadas de decisão do dia-a-dia. O Design é uma função, um recurso, e um modo de pensar, no contexto organizacional, que pode estar ativo no pensamento estratégico, no desenvolvimento de processos, e crucialmente, na implementação de projetos, sistemas e serviços (BEST, 2006).

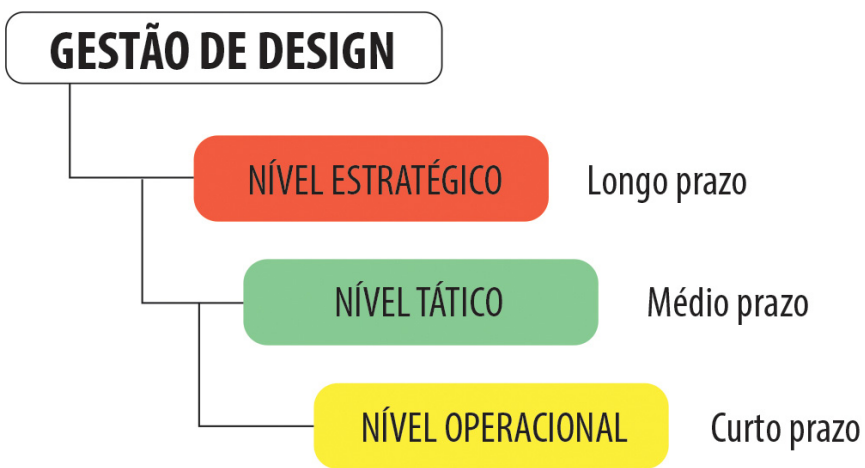

Figura II: Níveis da Gestão de Design Fonte: Adaptado BEST (2006) 
No nível estratégico da Gestão de Design encontram-se as ações e decisões estratégicas da empresa determinadas juntos aos dirigentes, como missão, visão, política empresarial, cultura organizacional e metas. Nessa área destacam-se a contribuição e coordenação de conhecimentos, recursos e práticas de Design visando criar valor, inovar e atingir os objetivos estabelecidos pela empresa.

É neste campo que um Gestor de Design deverá conciliar o papel do Design com a estratégia, a cultura e a identidade de uma organização tendo como principal objetivo o de controlar a consistência do trabalho de Design realizado na empresa, e também o de impor o Design no processo de formulação de estratégias gerais (MOZOTA, 2011). Nesse sentido, Seidel (2000) afirma que, o Design estratégico é uma contribuição valiosa para o desenvolvimento dos negócios auxiliando na compreensão da estratégia empresarial, buscando competências centrais, reunindo informações de mercado e inovando em processos de gerenciamento.

Segundo Mozota (2011), gerenciar o Design em um nível estratégico é administrar sua contribuição para o processo de formulação de estratégia: para definir a responsabilidade e a liderança atribuídas ao Design e sua contribuição à cultura organizacional, buscar oportunidades de inovações em Design e multiplicar demonstrações de identidade por meio do Design. Esse nível de Gestão de Design estabelece elos entre Design, comunicação corporativa e administração.

No nível tático ou funcional da Gestão de Design são destacados os recursos necessários para o Design; treinamento; descrição de processos e procedimentos e serviços e objetivos da equipe responsável pelo Design. É nessa área que o Design deve se integrar com as outras áreas da empresa, definindo e comunicando a estratégia de Design em relação à estratégia da empresa bem como divulgando o conhecimento de Design e coordenando a estratégia de Design com o marketing, inovação e comunicação.

"Nesta área da Gestão do Design, a natureza do Design torna-se uma função ou departamento e adquire a sua independência das outras áreas da empresa (MOZOTA, 2011, p.257)."

No nível operacional da Gestão de Design são realizados os projetos de Design, evidenciam-se a gestão do processo e da prática: criação do briefing, assegurando sua compreensão e interpretação; gestão de equipe de projeto e seleção de profissionais, definição de responsabilidades e prazos a serem cumpridos em cada fase ou processo; documentação e sistemas de controle; propostas; implementação das soluções e avaliação dos projetos de Design.

Procura-se neste espaço traduzir as estratégias e processos traçados num resultado final. Isto significa planejar e coordenar pessoas, partes interessadas, ou recursos necessários para a realização do projeto, dentro do prazo e do orçamento (BEST, 2006).

As capacidades e recursos provenientes do Design não devem ser promovidas de forma isolada ou apenas a curto prazo. $\mathrm{O}$ conhecimento que pode emergir em um processo multidimensional, que integre as competências em um processo dinâmico, envolva todos os stakeholders e invista constantemente em oportunidades, pode desencadear novas e potenciais respostas estratégicas tornando o Design uma competência central para as empresas (JEVNAKER, 2000).

A Gestão de Design, devido as suas características de gerenciamento, de inovação e de integração em ações tanto estratégicas quanto operacionais, vem sendo aplicada em empresas e organizações de diferentes setores como ferramenta de diferenciação competitiva.

\section{Identificação dos recursos e das competências da Gestão de Design para a sustentabilidade empresarial.}

De acordo com Papanek (1995), o Design preocupa-se com o desenvolvimento de produtos, utensílios, máquinas, artefatos e outros dispositivos, e esta atividade exerce uma grande influência sobre a ecologia. A resposta do Design deve ser positiva e unificadora; deve ser a ponte entre as necessidades humanas, a cultura e a ecologia. $\mathrm{O}$ autor acredita que existe uma evolução histórica das questões centrais colocadas por designers quando iniciam um projeto. Inicialmente, preocupavam-se com a questão estética "será que consigo fazer mais bonito?", em um segundo momento passou a ser "será que consigo fazer funcionar melhor?", para posteriormente evoluírem para "será que consigo fazer mais bonito e ao mesmo tempo funcionar melhor?". Então, surgiu a valorização da diferenciação: "será que consigo fazer de forma diferente?". Papanek acredita que as verdadeiras motivações deverão suscitar a colocação de questões como: "será que o Design irá auxiliar positivamente a 
sustentabilidade ambiental?", "poderá facilitar a vida de um grupo comunitário que foi excluído socialmente?", "poderá reduzir a dor?", "poderá poupar energia - ou melhor ainda - poderá utilizar energias renováveis?".

Complementando, acrescenta-se o que diz Charter e Tischner (2001), o desenvolvimento de produtos e serviços deverá ampliar suas áreas de atuação buscando envolver todos os aspectos do Triple Bottom Line, incluindo em cada etapa do processo critérios de avaliação dos impactos ambientais, sociais e financeiros.

Langer (2006) defende que, o Design será inútil sem uma nova reflexão em termos de valores ambientais, visto que a nossa sobrevivência depende do nosso sucesso em proteger o meio-ambiente e de projetar produtos e serviços de uma forma sustentável e econômica. $\mathrm{O}$ autor acredita que a sustentabilidade agrega valor, acima do desempenho do produto, além de ser um componente valioso de imagem corporativa que diferencia as marcas de uma forma positiva e persuasiva. As empresas podem ter um papel fundamental na promoção de produtos e serviços sustentáveis, beneficiando a si mesmos e ao meio ambiente.

"O principal desafio do design na contemporaneidade é, justamente, desenvolver e/ou suportar o desenvolvimento de soluções em questões de alta complexidade, que exigem uma visão alargada do projeto, envolvendo produtos, serviços e comunicação, de forma conjunta e sustentável (KRUCKEN, 2009, p.1)."

Neste cenário transitório, a gestão de design coloca-se como uma atividade contribuinte ao desenvolvimento sustentável, afirmando seu caráter sistêmico, metodológico e estratégico, estando esta diretamente envolvida com decisões nos meios de produção, comunicação, e, por tanto, de consumo (FIGUEIREDO e PALMIER, 2012).

\subsection{A Gestão estratégica de Design visando à sustentabilidade}

De acordo com Figueiredo e Palmier (2012) a Gestão de Design compartilha de ao menos duas características, para com o desenvolvimento sustentável embasamento sistêmico, visando a integração de diversos fatores em prol do funcionamento do todo, utilizando de uma visão cada vez mais abrangente e multidisciplinar e caráter estratégico, focado na continuidade, na otimização dos fatores necessários.

\section{GESTÃO DE DESIGN PARA A SUSTENTABILIDADE}

\section{NIVEL ESTRATÉGICO}

- Análise e diagnóstico do contexto interno (empresa) e externo (mercado)

- Identificação de oportunidades e novos modelos de negócio, de produção e de consumo

- Definição de estratégias e objetivos visando a melhoria da performance sustentável da empresa

- Mudança cultural e organizacional da empresa visando o desenvolvimento sustentável

Figura III: A Gestão estratégica de Design para a Sustentabilidade Fonte: Adaptado BEST (2006)

A partir de ferramentas e métodos de análise e diagnóstico, a Gestão estratégica de Design contribui para a identificação do contexto externo, analisando oportunidades e ameaças, compreendendo as necessidades do mercado e dos consumidores e para análise do contexto interno, identificando as competências internas, os pontos fortes e os pontos fracos da empresa. As informações resultantes dessa investigação devem apontar as oportunidades de intervenção do Design visando o desenvolvimento sustentável, contribuindo para a definição de estratégias que melhorem a performance sustentável da empresa e de seus produtos e serviços.

A Gestão estratégica de Design é potencialmente colaborativa para com a sustentabilidade, não só por atuar sobre a produção, mas por poder atuar em decisões em níveis corporativos, levando mudanças à política interna e ao foco empresarial, permitindo-a empregar soluções não apenas em produtos e comunicação gráfica, mas também em ambientes internos, comunicação de valores, 
conscientização, inovações tecnológicas e sociais, processos produtivos e elaboração de serviços, integrando-as de maneira coerente, em um sistema de soluções que forneçam suporte umas as outras, tendo maior condição de responder aos conflitos da transição (FIGUEIREDO e PALMIER, 2012).

Orssatto (2001) corrobora afirmando que, os gestores precisam primeiramente reconhecer que a vantagem competitiva pode ser incorporada não apenas nos produtos e serviços que eles vendem, mas também na forma como eles definem seus sistemas de produção e consumo. Esse reconhecimento irá permitir-lhes incorporar naturalmente estratégias ambientais de negócios na gestão global da empresa.

A Gestão de Design juntamente com a direção da empresa, são responsáveis pela definição dos objetivos e pela elaboração das estratégias para uma melhor adequação à visão de sustentabilidade. $O$ potencial da sustentabilidade deve ser incorporado ao longo de todo o processo, atuando não somente na definição da estratégia e na concepção e desenvolvimento de novas soluções para produtos e serviços, mas também levando a mudanças organizacionais e culturais na empresa. A Gestão estratégica de Design tem papel fundamental na partilha dos valores, ética, cultura organizacional e objetivos da empresa, devendo inserir as práticas sustentáveis no seu DNA, em qualquer atividade, operação e processo. Nesse nível, a Gestão de Design oportuniza a inovação em processos de gerenciamento, os quais são fundamentais para a reestruturação de uma empresa em busca de melhorias sociais, ambientais e econômicas.

Mozota (2011) afirma que, "O Design pode construir a vantagem competitiva de uma empresa externamente desenvolvendo uma oferta e uma posição única em um mercado e aprimorando internamente uma forte competência central." Identificar as questões ambientais associadas aos processos organizacionais e aos produtos e serviços vendidos pela empresa podem revelar oportunidades pelas quais as empresas podem otimizar seus esforços e, eventualmente, transformar investimentos ambientais em fontes de vantagem competitiva (ORSSATTO, 2001).

O resultado desse trabalho pode gerar vantagens competitivas significativas como: a percepção de uma imagem positiva da empresa junto a todos os stakeholders, a melhora do ambiente interno, o aumento no valor percebido dos produtos e serviços, maior fidelidade à marca e a conquista de novos consumidores.

\subsection{A Gestão tática de Design visando à sustentabilidade}

\section{GESTÃO DE DESIGN PARA A SUSTENTABILIDADE

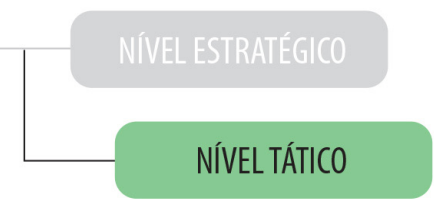 \\ - Visão sistêmica \\ - Promoção e conscientização de princípios, valores e práticas sustentáveis \\ - Identificação das prioridades e competências a serem desenvolvidas visando o desenvolvimento sustentável \\ - Integração de todos os stakeholders \\ - Comportamento colaborativo \\ - Interdisciplinaridade}

Figura IV: A Gestão tática de Design para a Sustentabilidade Fonte: Adaptado BEST (2006)

A Gestão tática de Design é responsável pela administração de um departamento de Design, assumindo as funções de liderança e coordenação dos recursos de Design em uma empresa. Nessa nível de gestão, o Design assume a função de integrar as estratégias e objetivos da empresa aos recursos do projeto, tendo papel fundamental na correta tradução dos objetivos em operações. Dessa forma, a Gestão tática de Design deve identificar as prioridades e competências que devem ser desenvolvidas para melhor utilização do Design com vistas à sustentabilidade. 
Esse nível de gestão deve assumir a função de incentivar e promover a alteração de valores e práticas sustentáveis, disseminando a conscientização e o conhecimento dos impactos que os projetos desenvolvidos terão durante todo o seu ciclo de vida. Para a condução de um processo de mudança visando à sustentabilidade é de suma importância o papel de todos os colaboradores. Ressalta-se aqui a importância da liderança como influenciador e promotor da mudança cultural e das práticas guiadas pelo desenvolvimento sustentável.

Em busca da sustentabilidade empresarial, uma empresa deve estar atenta as suas ações em todas as dimensões do desenvolvimento sustentável: econômica, social e ambiental. A Gestão tática de Design tem como principais características visão sistêmica e interdisciplinaridade, sendo responsável pela relação do departamento de Design com todos os setores da empresa, incentivando a integração e o comportamento colaborativo. Dessa forma, contribui para convergir os fluxos de informação e conhecimento de todas as áreas envolvidas no processo de desenvolvimento de produtos e serviços, fatores essenciais para a implementação do desenvolvimento sustentável. Essa visão holística e multidisciplinar potencializa a geração de novas ideias, de novas soluções e de inovação sustentáveis, com a colaboração das mais variadas áreas e competências da empresa, envolvendo todos os stakeholders e estabelecendo possíveis parcerias.

A Gestão tática de Design deve coordenar a estratégia de Design sustentável com o marketing, com a comunicação e com o desenvolvimento de produtos, definindo procedimentos e padrões mais sustentáveis.

\subsection{A Gestão operacional de Design visando à sustentabilidade}

\section{GESTÃO DE DESIGN PARA A SUSTENTABILIDADE}

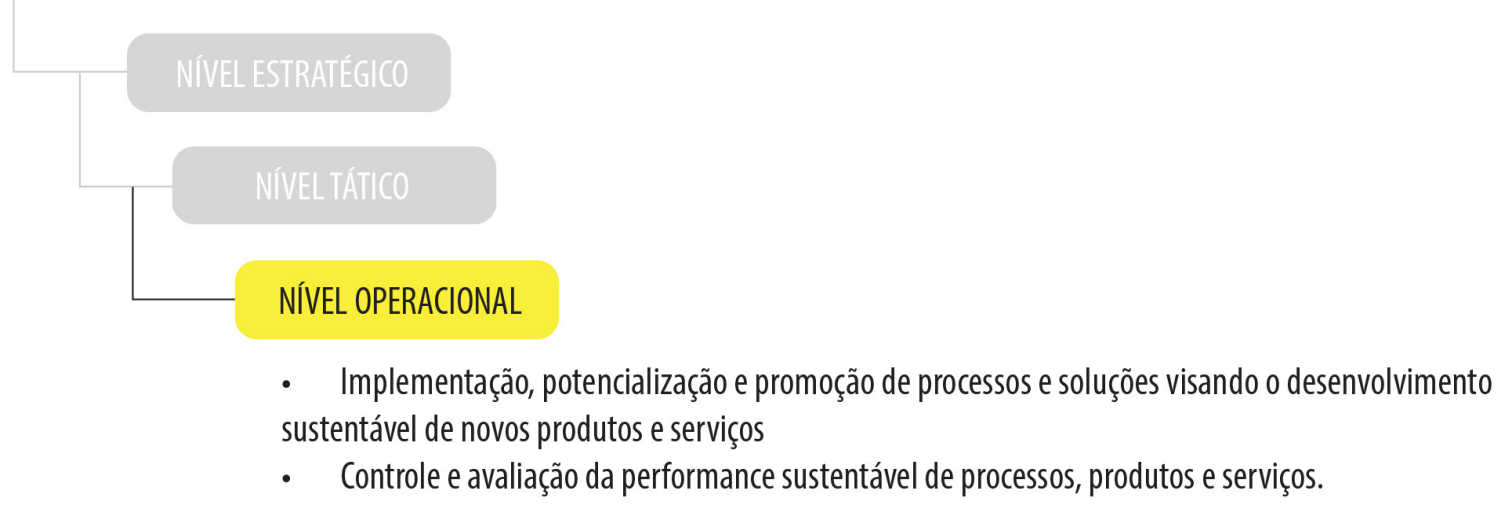

Figura V: A Gestão operacional de Design para a Sustentabilidade Fonte: Adaptado BEST (2006)

A Gestão operacional de Design está focada na responsabilidade pontual de cada projeto alinhado as estratégias da empresa. Nesse nível, a Gestão de Design desempenha um papel essencial na condução de processos de Design e desenvolvimento de soluções mais sustentáveis visto que o impacto ambiental e social de um produto ou serviço é definido no estágio de projeto. A Gestão de Design deverá implementar, potencializar, promover e avaliar métodos, técnicas, processos e projetos visando o desenvolvimento sustentável de novos produtos e serviços. Esse modelo de gestão, orientado ao usuário, também proporciona maior atenção aos detalhes e as necessidades dos consumidores.

Ressalta-se a importância do Gestor de Design no controle, orientação e avaliação dos projetos, certificando-se que correspondem aos objetivos e estratégias definidas pela empresa bem como aos critérios de aferição da sustentabilidade estabelecidos.

A performance sustentável de um produto ou serviço pode ser avaliada através da Análise do Ciclo de Vida - LCA (Life Cycle Analysis), que pode ser definida como a compilação e avaliação dos "inputs" e "outputs" e potenciais impactos ambientais do sistema de um produto ou serviço ao longo do seu ciclo de vida. A $L C A$ é uma ferramenta de análise do peso ambiental dos produtos em todas as fases do seu ciclo de vida - da extração de recursos passando pela produção de materiais, componentes ou do produto em si, pelo período de utilização do mesmo, e ainda no momento em que este é descartado (Guinée, 2001).

O método de Análise do Ciclo de Vida fragmenta os produtos manufaturados em todas as suas partes componentes e processos industriais, medindo com precisão seus impactos ambientais e sociais desde a extração de materiais, passando pela produção até sua eliminação. 
O estudo dos impactos ambientais cobre todos os tipos de influência no ambiente, como as emissões de gases tóxicos, a extração de recursos naturais e utilização da terra, consumo de água e energia, entre outros. Esta avaliação resulta numa ferramenta de cálculo e quantificação desses impactos possibilitando, desta forma, fornecer um conjunto de dados claros relativos ao produto que se pretende desenvolver. No entanto, esta análise exige uma compreensão profunda das implicações de cada fase bem como das alternativas ou soluções que surgem (Guinée, 2001).

O impacto da Gestão de Design associado ao desenvolvimento sustentável pode contribuir na concepção de projetos mais sustentáveis, resultando em melhorias na usabilidade, na eficiência produtiva, na otimização de recursos, na eliminação de desperdícios, na redução de custos e consequente aumento de lucros, no aumento de qualidade, no desenvolvimento de novas tecnologias, na inovação, na criação de novas necessidades nos consumidores e em oportunidades de novos negócios.

\section{Conclusão}

O movimento de sustentabilidade cresce em escala mundial, e as preocupações com as questões sociais e ambientais são irreversíveis para um futuro mais promissor. Os padrões de consumo e de produção atuais são insustentáveis, dessa forma, é imprescindível uma mudança no nosso estilo de vida e no sistema produtivo, sendo estes partes essenciais nos impactos ambiental, social e econômico. Nesse contexto, as empresas são em grande parte responsáveis pela solução dos problemas socioambientais existentes, possuindo maiores recursos para uma mudança de paradigma visando à sustentabilidade.

O conceito de desenvolvimento sustentável visa o equilíbrio, buscando garantias de bem-estar social, ambiental e econômico desta e das futuras gerações. Os consumidores conscientes passam, cada vez mais, a valorizar as práticas sustentáveis. Desejam que as empresas não sejam parte do problema, mas da solução. Por outro lado, as empresas percebem que a sustentabilidade empresarial configura-se como uma oportunidade de negócios e de vantagem mercadológica.

Para uma empresa viabilizar a sustentabilidade deve ter uma visão sistêmica, analisando a interdependência de todas as dimensões do negócio; deve investir em inovação; melhorar o bem estar de seus funcionários e consumidores; investir em práticas sociais; preocupar-se com a gestão sustentável em toda a sua cadeia e com a análise do ciclo de vida de seus produtos, buscando reduzir ao mínimo o seu impacto ambiental e social. Quando isso não for possível, deve compensar suas "pegadas" com ações efetivas.

"Inovar seguindo as três dimensões da sustentabilidade ainda não é regra, até porque a inclusão das dimensões sociais e ambientais requer novos instrumentos e modelos de gestão, que só recentemente começaram a ser desenvolvidos com mais intensidade." (BARBIERI et al, 2010, p.152)

A sustentabilidade empresarial é uma mudança complexa, que exige uma modificação organizacional e cultural por parte das empresas. Para que isso ocorra ressalta-se a importância de inovações no processo de gerenciamento. A Gestão de Design, afirmando seu caráter estratégico, metodológico, comunicativo, colaborativo e integrador, configura-se como uma ferramenta significativa na contribuição para essa mudança de paradigma.

No nível estratégico, a Gestão de Design visando à sustentabilidade, verifica e desenvolve novas oportunidades de mercado, define objetivos e estratégias voltados ao desenvolvimento sustentável, melhora a imagem corporativa e aumenta o valor percebido de produtos e serviços bem como o valor de marca. No nível tático, a Gestão de Design com sua visão sistêmica e interdisciplinar, integra, promove e comunica valores e práticas mais responsáveis, contribuindo na mudança comportamental de todos os stakeholders e na melhoria do ambiente de trabalho. No nível operacional, a Gestão de Design, traduz os objetivos e estratégias em produtos e serviços sustentáveis, com melhorias na eficiência produtiva, na redução de custos, na eliminação de desperdícios, na usabilidade e nos impactos sociais. É também nesse nível que se dá a avaliação dos processos e projetos segundo os critérios da sustentabilidade.

A Gestão de Design, associada ao desenvolvimento sustentável, impacta positivamente na concepção de projetos mais sustentáveis, otimizando o processo de produção, os recursos, a eficiência, a distribuição no mercado, o descarte ou reuso e oportunizando melhorias sociais. 
Concluindo, as análises teóricas na perspectiva da contribuição da Gestão de Design à sustentabilidade empresarial, indicam que os recursos e competências desse modelo de gerenciamento são relevantes na elaboração de estratégias e projetos consentâneos com as três dimensões da sustentabilidade com resultados duradouros. Se praticada de forma eficiente, a Gestão de Design visando à sustentabilidade resultará em inovação, novas oportunidade de negócios, aumentos nos lucros, criação de valor percebido e um diferencial competitivo significativo em um mercado de concorrência acirrada e de produtos e serviços similares.

\section{The Contribution of Design Management to Corporate sustainability.}

Abstract: The setting of the current society needs a paradigm shift on the part of citizens, businesses and governments. It is necessary to review our way of life and reinvent the models of production, development and consumption, reconciling the economic, environmental and social dimensions in business, for the prosperity of the companies and our future. According to Manzini (2006), we need to find a new way of life in line with the sustainability paradigm. In this case, the term "sustainable development" refers to a demand to meet the present needs of production and consumption without compromising the future generations. Design is a creative activity whose purpose is to establish the multifaceted qualities of objects, processes, services and their systems throughout the life cycle (ICSID). In the era of mass production, where everything has to be planned and designed, Design has become one of the most powerful tools with which man shapes his tools and his environment, by extension, to society and to himself (PAPANEK, 1995). Design consists of improving the quality of use of the product, the shape of a new product, its manufacturing process, environmental and social sustainability, access to a socially inclusive product, application of new materials and aesthetic quality (BONSIEPE, 1997). Manzini and Vezzoli (2008) argue that the product should be designed considering at all stages the concept of life cycle, in all the activities necessary to produce, distribute, use and eliminate/discard a product are considered one unit. Design Management has emerged, although focused on competitiveness, from the perception that the Design activity can contribute to the entrepreneurial orientation through its design character, regarding the arrangement of factors that determine an innovative path towards a goal (MARTINS and MERINO, 2011). This theoretical work aims to analyze the contribution of Design Management as a promoter of social, environmental and economic improvements in the business context, while evaluating the influence of adoption of corporate sustainability practices for success within marketing, philosophical and financial in companies. Therefore, this paper first analyzes the global context on sustainable development and appraises corporate sustainability, to follow, to address the concepts of Design Management. Finally, it analyzes Design Management's contribution towards sustainable development in companies and their benefits in business performance.

Keywords: Sustainable Development; Companies; Design Management.

\section{Referências bibliográficas}

ALESSIO, R. Responsabilidade social das empresas no Brasil: reprodução de postura ou novos rumos?, EDIPUCRS. Porto Alegre: 2008.

ALMEIDA, F. O bom negócio da sustentabilidade, Nova Fronteira. Rio de Janeiro: 2002.

BAHIANA, C. A importância do Design para sua empresa, CNI, COMPI, SENAI/DR-RJ. Brasília: 1998.

BARBIERI, J. C. et al. Inovação e Sustentabilidade: Novos Modelos e Proposições. Revista de administração de empresas RAE/FGV. São Paulo: vol. 50, n. 2, abr-jun 2010.

BARBIERI, J. C.; CAJAZEIRA, J. E. R. Responsabilidade social empresarial e empresa sustentável: da teoria à prática, Editora Saraiva. São Paulo: 2009.

BEST, K. Design Management: managing Design strategy, process and implementation, AVA Publishing. Suiça: 2006. 
BOVESPA. BM\&FBOVESPA divulga a carteira do Índice de Sustentabilidade Empresarial para 2014. Brasil, 2014, 3p. Disponível em: <http://www.bmfbovespa.com.br/Indices/download/Carteira-ISE-2014.pdf> Acesso em: 20 jan. 2015.

BRUNDTLAND, G. et al. Our Common Future: The World Commission on Environment and Developmen, ONU. Nova York: 1987.

CASTELLS, M. O poder da identidade, Paz e Terra. São Paulo: 1999.

CHARTER, M.; TISCHNER, U. Sustainable Solutions - Developing Products and Services for the Future, Greenleaf Publishing Limited. Sheffield: 2001.

CLUB OF ROME. About the Club OF Rome. Suiça. Disponível em: <http://www.clubofrome.org>. Acesso em: 15 abril 2015.

CMMAD. Comissão Mundial sobre Meio Ambiente e Desenvolvimento. Nosso Futuro Comum, Editora da Fundação Getúlio Vargas. Rio de Janeiro: 1991.

THE ECONOMIST. Doing good: business and the sustainability challenge. Inglaterra, 2008, 53p. Disponível em: <http://www.economistinsights.com/business-strategy/analysis/doing-good> Acesso em: 24 jun. 2015.

ELKINGTON, J. Cannibals with Forks: The Triple Bottom Line of 21st Century Business, Capstone Publishing Ltd. Oxford: 1997.

FIGUEIREDO, Luiz Fernando Gonçalves de; PALMIER, Alberto Ribeiro. VIII CONGRESSO NACIONAL DE EXCELêNCIA EM GESTÃO, 8., 2012, Niterói. Contribuição ao discurso da Gestão de Design como um ativo na transição ao desenvolvimento sustentável. Niterói, RJ: Universidade Federal Fluminense, 2012. 20 p. Disponível em: <http://www.inovarse.org/node/1396>. Acesso em: 06 abr. 2017.

GUINÉE, J. et al. Life Cycle Assessment - An Operational Guide to the ISO Standards, Leiden University. Final Report, Center of Environment Science, 2001.

ICSDI - International Council Societies of Industrial Design. Disponível em: <http://www.icsid.org>. Acesso em 01 maio 2015.

IDSA - Industrial Designers Society of America. Disponível em: <http://www.idsa.org>. Acesso em 01 maio 2015.

INSTITUTO AKATU. Estilos sustentáveis de vida. Resultados de uma pesquisa com jovens brasileiros. Brasil, 2009, 44p. Disponível em: <http://www.akatu.org.br/Content/Akatu/Arquivos/file/Publicacoes/EstilosSustentaveisdeVida.pdf>. Acesso em: 10 fev. 2015.

INSTITUTO ETHOS DE EMPRESAS E RESPONSABILIDADE SOCIAL. Princípios e compromissos. São Paulo. Disponível em: <http://www3.ethos.org.br/>. Acesso em: 20 jan. 2015.

JEVNAKER, B. H. How Design Becomes Strategic. Design Management Journal, vol.11, no. 1, Winter, 2000. Disponível em: < http://onlinelibrary.wiley.com/doi/10.1111/j.19487169.2000.tb00286.x/epdf >. Acesso em: 22 junho 2015.

KOTLER, P.; KARTAJAYA, H.; SETIAWAN, I. Marketing 3.0: as forças que estão definindo o novo marketing centrado no ser humano, Elsevier. Rio de Janeiro: 2010.

LANGER, H. The potential of Design to communicate value, International Council of Design. Quebec: 2006, 3p. Disponível em: <http://www.ico-d.org/connect/features/post/223.php>. Acesso em: 15 abril 2015.

LOUETTE, A. (Org.). Compendio para a sustentabilidade: Ferramentas de Gestão de responsabilidade Socioambiental, Antakarana Cultura Arte Ciência. São Paulo: 2008.

MAGALHÃES, C. Design Estratégico: integração e ação do Design industrial dentro das empresas. SENAI/DN- SENAI/CETIQT - CNPq - IBICT - TIB. Rio de Janeiro: 1997.

MARTINS, R. F. de F.; MERINO, E. A. D. A gestão de Design como estratégia organizacional, Rio Books. Rio de Janeiro: 2011. 
MANZINI, E. Design, Ethics and Sustainability - Guidelines for a Transition Phase, Politenico de Milão. Milão: 2006.

MOZOTA, B. B. de. Gestão de Design: usando o Design para construir valor de marca e inovação corporativa, Bookman. Porto Alegre: 2011.

NIELSEN GLOBAL REPORT. It pays to be green: corporate social responsibility meets the bottom line. United States of America, 2014. 7p. Disponível em: <http://www.nielsen.com/us/en/insights/news/2014/it-pays-to-be-green-corporate-socialresponsibility-meets-the-bottom-line.html>. Acesso em: 13 fev. 2015.

ORSSATTO, R. J. Market advantage and environmental strategies of firms: competitive rationales for proactive environmental management. In: Ninth International Conference of Greening of Industry Network Bangkok, Sustainability at the Millenium: Globalization, Competitiveness and the Public Trust, 2001, 19p. Disponível em: <https://scholar.google.com.br/scholar?q=Market+advantage+and+environmental+strategies+of +firms: +competitive+rationales+for+proactive+environmental+management\&hl=ptBR\&as_sdt=0\&as _vis=1\&oi=scholart\&sa=X\&ei=ZUskVZPCEPX_sASSzIHoDA\&ved=0CB4QgQMwAA>. Acesso em: 07 abril 2015.

PAPANEK, V. The Green Imperative - Ecology and Ethics in Design and Architecture, Thames and Hudson. Londres: 1995.

PINHEIROS, M. D. Ambiente e Construção Sustentável, Instituto do Ambiente. Lisboa: 2006.

SACHS, I. Caminhos para o Desenvolvimento Sustentável. Garamond. Rio de Janeiro: 2002.

SEIDEL, V. Moving from Design to Strategy: The 4 roles of Design-Led strategy consulting. Design Management Journal, vol.11, no. 2, Spring, 2000. Disponível em: <http://onlinelibrary.wiley.com/doi/10.1111/j.1948-7169.2000.tb00017.x/epdf>. Acesso em: 20 junho 2015.

UNDSD. Agenda 21 - United Nations Conference on Environment \& Development, United Nations Division for Sustainable Development. Rio de Janeiro: 1992.

WOLF, B. O Design Management como fator de sucesso, ABIPT/SEBRAE/IEL/Programa Catarinense de Design. Florianópolis: 1998. 